\title{
The Relationship Between Developmental Trajectories Of Girls' Offending And Police Charges: Results From The Pittsburgh Girls Study
}

\author{
Lia Ahonen ${ }^{1,2}$ (D) Wesley G. Jennings ${ }^{3}$. \\ Rolf Loeber $^{1}$ - David P. Farrington ${ }^{4}$
}

Received: 10 January 2016 / Revised: 26 April 2016 / Accepted: 18 June 2016 /

Published online: 1 July 2016

(C) Springer International Publishing AG 2016

\begin{abstract}
The current study is based on longitudinal self-reported data from the Pittsburgh Girls Study $(N=2,450)$. This is the largest follow-up delinquency study of girls in the USA; an inner-city population of girls, between the ages of 11 and 18. We first investigated self-reported developmental trajectories for delinquency, and we then examined the correspondence between these selfreported delinquency trajectories and later police charges. The results show three self-reported delinquency trajectories for the PGS participants: non-offenders, low-rate offenders, and high-rate offenders. Further, the high-rate offenders also differed in kind in addition to in degree as they were more versatile offenders demonstrating notable involvement in both property and violent offending relative to the low-rate offenders. Additional analyses revealed that these self-reported trajectories were significantly associated with the frequency and the odds of official offending according to police charges during this same time period (i.e., ages 11-18). Study limitations and implications for future trajectory-based research with female samples are discussed.
\end{abstract}

Keywords Developmental trajectories · Females · Delinquency · Self-reports · Official records

Lia Ahonen

ahonen1@upmc.edu

1 University of Pittsburgh, Pittsburgh, PA, USA

2 Örebro University, Örebro, Sweden

3 University of South Florida, Tampa, FL, USA

4 Cambridge University, Cambridge, UK 


\section{Introduction}

There are several reasons why female delinquency is much less well understood than the delinquency of males. First, research on delinquency and its development over time has historically been male-oriented (e.g., [1-3]). Second, female compared to male delinquency is overall much more difficult to study because of the lower base rate of delinquency and the changing types of offense and arrest patterns. For example, the inclusion criteria for simple assault have changed (now including family disputes), zero-tolerance policies in schools have led to an increase in officially recoded offenses, and in addition there have been local law enforcement changes resulting in the lowering of the thresholds for recording assault and aggravated assault (e.g., [4]). Zahn et al. [4] also showed, based on national statistics, that the gender gap in delinquency when counting arrests has narrowed in the past decades, although this is more evident from official records than from self-reported delinquency (also see [5, 6]).

There is yet little consensus about the development of female delinquency over time. In criminology, one of the most consistent findings is the aggregate age-crime curve (e.g., $[7,8])$. This curve has a bell-shaped distribution, with a small percentage of young individuals engaging in delinquent activity in late childhood, followed by a major increase in delinquency in mid-adolescence and a subsequent decrease in early adulthood. The age-crime curve has been tested with different outcomes and covariates including neighborhood disadvantage (e.g., [9]), age differences in economic disadvantage (e.g., [10]), and neural research [11] to mention a few. The results are conclusive, showing that the age-crime curve for male samples is mostly replicable. Since the curve for males seems stable over different study designs, it is unfortunate that there is still a scarcity of attempts to investigate the age-crime curve for females (e.g., $[12,13])$.

Although a growing number of studies have investigated the prevalence and frequency of female delinquency (e.g., $[5,14]$ ), very few projects have examined the age-crime curve for girls in the USA (but see international studies such as $[15,16]$ ). In one notable exception, Loeber et al. [13] found that the age-crime curves for both prevalence and frequency were rather flat for girls compared to those of boys. We hypothesize, however, that since there are large individual differences in the frequency of offending among girls, the aggregate age-crime curve may hide the presence of a subgroup of girls whose delinquency between late childhood and late adolescence is more sharply peaked and versatile. One way to investigate this hypothesis is to undertake trajectory analyses, which are designed to reveal the age-crime curves of subgroups of individuals who may be different from the aggregate curve. However, trajectory analyses and similar analyses of long-term development of delinquency in large female samples are still scarce (but see [17-21]). Most of these studies deal with smaller samples, specific aspects of delinquency such as aggression, or only official records of offending. Jennings et al. [22] found that the pathways of offending may be more similar than different across gender, although males compared to females are more likely to belong to categories of offenders labeled as high-rate chronic offenders, escalators or chronic aggressive individuals [23, 24]. In addition, males are more likely to belong to what Moffitt referred to as life course persistent offenders, who often have an early onset of offending [25]. Other studies have found that the trajectories for young males and females are different, that the trajectories for females were much less predictable over a six-year span [26], and that female delinquency, to a larger extent 
than for males, was characterized by intermittency in offending (i.e., stopping and starting up again) (e.g., [18]).

Previous trajectory research has also discovered fewer trajectories for females than for males. Results from studies on males (in offender samples) usually show between four and six mutually exclusive trajectories of antisocial development (e.g., [27]: [28]). Piquero's review [29] initially concluded that it was common among the reviewed studies for trajectory analyses of male offender samples to show four trajectories, but when the samples were followed up at later ages, there were as many as six trajectories (e.g., [30]). There are a number of alternative explanations for these different results. First, they may be attributable to different types of measurement and different ages of measurement. Second, with age, there are increasing numbers of confounding factors that could change the direction and characteristics of antisocial behavior, including being involved in a prosocial marriage (e.g., [28]). In a study of six general population samples (compared to offender samples above) of males, Broidy et al. [31] found four or more trajectories for males. In the Cambridge Study in Delinquent Development, Farrington et al. [1] found that the number of trajectories for males increased from four to five as the follow-up period increased from ages 10 to 24 to ages 10 to 56. Turning to females, Piquero [29] showed in his review of 80 trajectory studies that most studies found a smaller number of trajectories for females than for males, typically only two or three (see also, [32]).

The present study investigates developmental trajectories of self-reported delinquency for young females in a large longitudinal sample to determine if there are unique female offending profiles. This study will also examine the extent to which self-reported delinquency trajectory membership is associated with officially recorded police charges for delinquent acts, and whether different developmental trajectories for females differ not only by their frequency of offending but also in kind, that is, the versatility of types of offenses committed. This knowledge is important in estimating the true volume of crime from official records, in evaluating the effectiveness and cost-effectiveness of intervention techniques, and in measuring the effectiveness of the criminal justice system [33]. In addition, this knowledge is useful to both policy makers and service providers in the intervention field, in the design and execution of intervention programs, and to distribute financial resources more effectively.

\section{The Current Study}

The current study addresses the following questions:

Are there distinct trajectories of girls' delinquency based on their self-reported offending for moderate and serious theft and violence, and do these trajectories differ in kind?

Are the self-reported developmental trajectories of girls' delinquency at ages 11 to 18 differentially associated with officially recorded delinquency during this same time period (i.e., ages 11-18)?

\section{Methods}

The Pittsburgh Girls Study (PGS) is a longitudinal study with yearly follow-ups of girls in the city of Pittsburgh, which started in 1999/2000 [34]. The PGS is based on a large 
community sample of 2450 girls, with the first assessment at very early ages (ages 5, 6, 7 , and 8 for the four cohorts, respectively) and multiple informants (girls, caregivers, teachers, and official records). The main focus of the study is to investigate the development of mental health problems, delinquency, substance use, and prosocial behavior from middle childhood into early adulthood.

Because the overall base rate of delinquency and behavioral problems is lower among females than males, girls in the most disadvantaged neighborhoods (according to US Census data) were oversampled (100\% in the 23 disadvantaged neighborhoods, $50 \%$ in the 66 advantaged neighborhoods). The main aim of this was to increase the number of high-risk girls (for more details see [34]). In order to investigate trajectories of girls' delinquency development, the current study used self-reported data and official charges from ages 11 to 18 (eight consecutive yearly assessments, waves 5-12).

The four age-based cohorts did not significantly differ by SES, living conditions, or family constellation (i.e., single-parent vs. two-parent households), and so all four cohorts were merged for the current analyses. The initial participation rate for the four age cohorts was $85 \%$ of all identified families that were eligible for participation in the study. The study has an overall average retention rate of over $90 \%$, across all assessment waves.

The racial distribution at the initial assessment was as follows: $52.9 \%$ of the girls were African-American, $41.2 \%$ were white Caucasian, and $5.9 \%$ were reported as another race (or mixed race). At the initial assessment, the majority (93\%) of the girls were living with their biological mother. Most of the girls attended public schools at age $11(82.6 \%) ; 16.5 \%$ attended private schools, and only a fraction $(0.9 \%)$ were homeschooled. There were no statistically significant differences in the distribution of types of schools over the four different cohorts.

Attrition analyses were conducted to compare the demographic characteristics of girls at wave 1 who declined further participation through wave 11 with those who continued in the study [34]. No statistically significant differences between those who dropped out and those who continued were observed for ethnicity, parent education, or single parent status. Public assistance was more frequent in families who dropped out of the study. Taken together, the PGS disproportionately lost participants that were at higher risk for delinquency, but the magnitude of that loss was not large. Importantly, since no other demographics differed between the remainders and the dropouts, and the overall retention rate was remarkably high, no further attrition analyses were called for or conducted. Additional details of how the PGS team ensured high participation rates, including information on the data, can be found in Keenan et al. [35].

\section{Measures}

Self-reported delinquency Self-reported delinquency was measured on a yearly basis using the Self-Reported Delinquency Questionnaire (SRD). The 40 items of the SRD are based on the National Youth Survey and have been widely evaluated (e.g., [36, 37]). We used a conservative approach indexing delinquency, and thus we did not include status offenses or minor offending. Specifically, the following moderate and serious 
theft items were included: stealing more than US\$5, pickpocketing, stealing from a car, dealing in stolen goods, breaking and entering, joyriding, and stealing a car. The moderate and serious violence items included gang fighting, robbery, assault, and attacking with a weapon. Each girl reported whether or not she had committed a particular offense type in the previous 12 months and, if so, how many times. The response alternatives ranged from zero to the exact number with no upper limit.

Officially recorded police charges We used juvenile records of police charges from age 11 to age 17 to investigate whether the girls had been charged with any moderate or serious theft or violent offenses. Juvenile records were acquired from Allegheny County Juvenile Probation Office (JPO), which provided county-wide data on participants aged 17 and younger according to their name, current address(es), date of birth and/or Social Security number (SSN). Valid data on delinquency charges was available for $91-94 \%$ of the entire sample (range $N=2224$ to 2302 over the four cohorts). Charges were missing for a small number of girls who had moved out of the county or were deceased by the age of $17(n=7)$. Further, we used criminal records at age 18 , and every PGS participant was searched in the Court of Common Pleas web docket system for Pennsylvania. Dockets were identified in two ways: first three letters of first name and first three letters of last name + date of birth or the full first and last name, and blank date of birth. If records were found using either method, they were considered a match. All found dockets were printed and double-entered into a database. The following charges were included for theft obtained from the juvenile and adult criminal records: larceny, selling stolen property, burglary, and unauthorized use of a motor vehicle. Violence charges obtained from the juvenile and adult criminal records included: assault (all types), robbery, and carjacking. For further details on the categorization of charges, see [38].

\section{Analytic Strategy}

The analysis plan proceeded in three stages. In the first stage, trajectory models were estimated using the PROC TRAJ macro [39] for the PGS study participants based on their self-reported offending of moderate or serious theft or violence from ages 11 to 18 . Specifically, the trajectories were estimated through an iterative modeling process whereby various parametric forms (constant, linear, quadratic, and cubic) were assessed as well as examining various numbers of possible trajectory groups before ultimately arriving at the most optimal trajectory solution. The primary methods for final model selection included an examination of the Bayesian Information Criteria (BIC) and an evaluation of model precision, which was determined through a review of the mean posterior probabilities of group assignment [40, 41]. Similar to the bulk of prior developmental/life-course trajectory-based research (for example, see [1]: [2]), we relied on the zero-inflated Poisson functional trajectory form (or what is commonly referred to as the ZIP model) because of the apparent skewness of the self-reported offending frequency outcome. In addition, because of the research design of the PGS, sampling weights to correct for the original over sampling were incorporated into the trajectory analyses, to estimate results for the original population of girls. 
In the second stage of the analysis, using a chi-square $\left(\chi^{2}\right)$ test we examined to what degree individuals in divergent trajectories differed in their versatility of self-reported offending, specifically their involvement in moderate/serious theft and moderate/ serious violence.

In the third stage of the analysis, officially recorded charges for moderate and serious theft and/or violence from ages 11 to 18 were analyzed for the PGS study participants classified in the self-reported delinquency trajectories estimated in stage one of the analysis. Specifically, chi-square $\left(\chi^{2}\right)$ tests, an ANOVA with post hoc tests, and a series of bivariate logistic regression models are estimated to evaluate the association between the PGS self-reported delinquency trajectories and (1) the frequency of officially recorded charges for moderate and serious theft and/or violence; (2) the prevalence of involvement in moderate/serious theft compared to the prevalence of involvement in moderate/serious violence; and (3) the odds of having an officially recorded charge for moderate and serious theft and/or violence.

\section{Results}

Figure 1 displays the trajectory solution for the PGS moderate and serious theft and/or violence self-reported delinquency trajectories; the trajectory group prevalence estimates and the mean posterior probabilities for group assignment are presented in Table 1. As can be seen, a three-group, quadratic trajectory solution was determined to be the best-fitting trajectory model, and these trajectories are labeled as nonoffenders, low-rate offenders, and high-rate offenders. ${ }^{1}$ The mean posterior probabilities for group assignment ranged from 0.93 to 0.99 , well above the 0.70 threshold provided by Nagin $[40,41]$ as an indicator of trajectory model precision. Regarding the trajectory groups, the non-offenders, who exhibited very little to no offending between ages 11 and 18, comprised $77.5 \%$ of the sample. In contrast, the low-rate offender trajectory $(20.7 \%)$ began offending at low rates, had a low peak at ages 14/15 averaging nearly 1.5 offenses per trajectory group member, and declined by age 18 . These low-rate trajectory group members averaged 9.68 offenses $(\mathrm{SD}=8.84)$ between the ages of 11 and 18 with a range of two to 55 offenses. Comparatively, the PGS girls classified into the high-rate trajectory were averaging approximately six offenses at age 11, peaked at ages 15/16 where they averaged over nine offenses, and then declined by age 18 to average nearly 7.5 offenses per trajectory group member. In total, these 44

\footnotetext{
${ }^{1}$ The quadratic model was the best-fitting parametric form for the trajectory model as the low and high-rate trajectories exhibited only one directional change rather than being linear or cubic in their developmental progression. Linear and cubic models were estimated nonetheless, and the BIC values provided evidence that the quadratic model was the best fit as far as the parametric form of the trajectory model. Specifically, the BIC value for the three-group quadratic trajectory model was -10776.54 , compared to the BIC values of -10855.75 for the three-group linear trajectory model and -10819.54 for the three-group cubic trajectory model. Furthermore, the BIC value for the two-group quadratic trajectory model was -11471.72 , and the four-group quadratic trajectory model converged but the parameter estimates for three of the four groups were not statistically significant. In addition, the odds of correct classification based on the posterior probabilities of group assignment for the three-group quadratic trajectory model all exceeded the recommended threshold of 5 [42]. These model selection criteria, along with an examination of the mean posterior probabilities of group assignment, ultimately provided evidence that the three-group quadratic model was the most optimal trajectory solution.
} 


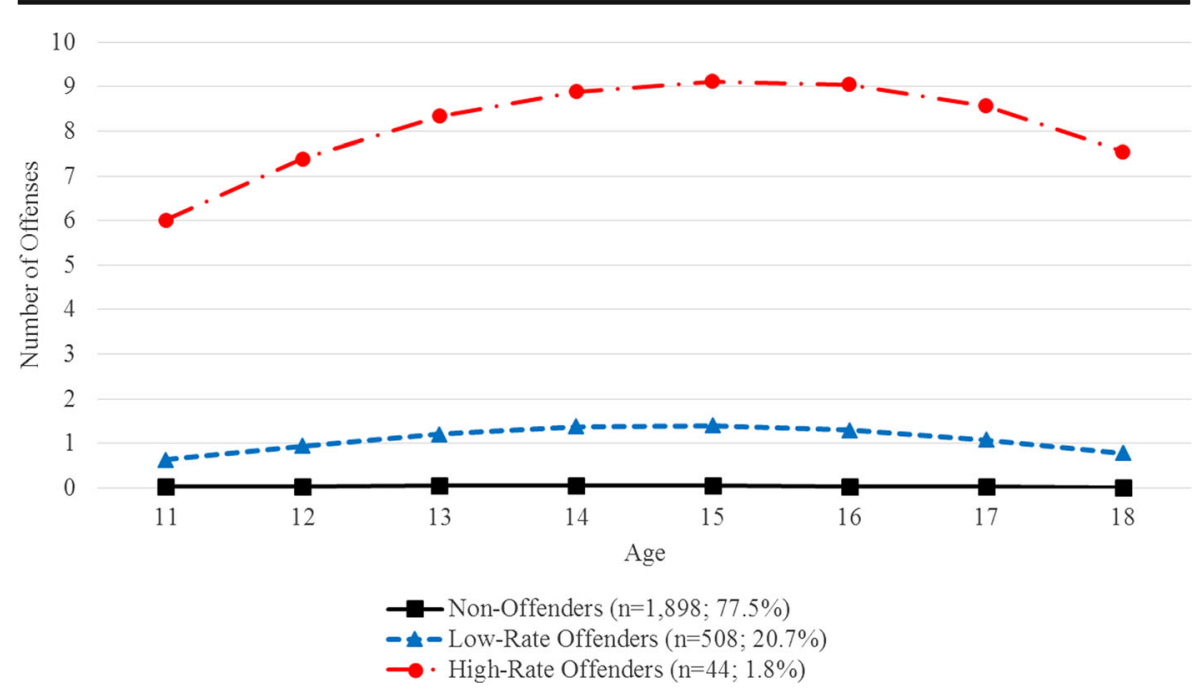

Fig. 1 PGS moderate and serious theft and violence self-reported offending trajectories, ages 11-18

PGS girls (1.8\% of the sample) who were classified as high-rate offenders averaged 77.55 offenses in total $(\mathrm{SD}=55.29)$, committed between 15 and 247 offenses each, and were responsible for committing nearly one out of every three offenses self-reported by the entire sample.

Next, we investigated the differences in the prevalence of girls' moderate/serious theft and violence in the low and high trajectory groups between the ages of 11 and 18 . The two trajectory groups differed in kind (e.g., type of offending) beyond just a significant difference in the degree/frequency of offending. The results indicated that the prevalence of moderate/serious theft was $46.0 \%$ for the low-rate offender trajectory and $69.2 \%$ for the high-rate offender trajectory $\left(\chi^{2}=486.93, p<.001\right)$. In contrast, the prevalence of involvement in moderate and serious violence was $92.3 \%$ for the lowrate offender trajectory and $89.7 \%$ for the high-rate offender trajectory $\left(\chi^{2}=888.73\right.$, $p<.001)$. In addition, a subsequent chi-square analysis indicated that $59.0 \%$ of the offenders in the high-rate trajectory committed both moderate/serious theft and moderate/serious violence offenses, compared to only $38.3 \%$ of the offenders in the low-rate offender trajectory $\left(\chi^{2}=1063.08, p<.001\right)$. Taken together, these findings

Table 1 Trajectory prevalence and mean posterior probabilities for group assignment for PGS moderate and serious theft and violence self-reported offending trajectories, ages 11-18

\begin{tabular}{lllll}
\hline & \multirow{2}{*}{$\begin{array}{l}\text { Trajectory prevalence } \\
\%\end{array}$} & $\begin{array}{l}\text { Mean posterior probabilities } \\
\text { mean }\end{array}$ & \multicolumn{2}{l}{$\begin{array}{l}95 \% \text { confidence interval for } \\
\text { mean }\end{array}$} \\
\cline { 4 - 5 } & & & Lower & Upper \\
\hline Non-offenders & $77.5 \%$ & 0.94 & 0.93 & 0.94 \\
Low-rate offenders & $20.7 \%$ & 0.93 & 0.91 & 0.94 \\
High-rate offenders & $1.8 \%$ & 0.99 & 0.99 & 1.00 \\
Total & $100 \%$ & & & \\
\hline
\end{tabular}


suggest that the high-rate offender trajectory is different from the low-rate offender trajectory not only in degree (e.g., offend at a higher frequency) but also in kind (e.g., more versatile offenders demonstrating notable involvement in both property and violent offending).

Figure 2 shows that there were also statistically significant mean differences in the frequency of officially recorded charges across the self-reported trajectories $(F=39.43$, $d f=2, p<0.001)$. On average, the PGS girls in the self-reported non-offender trajectory averaged $0.18(\mathrm{SE}=0.02)$ officially recorded charges between ages $11-18$, whereas the girls in the self-reported low-rate offender trajectory averaged nearly 3-4 times the mean number of officially recorded charges between ages 11 and $18(M=0.66$, $\mathrm{SE}=0.08$ ) relative to those classified in the self-reported non-offender trajectory (see Fig. 2). In contrast, the PGS girls assigned to the self-reported high-rate offender trajectory averaged more than five times the mean number of officially recorded charges $(M=0.93, \mathrm{SE}=0.23)$ relative to those in the self-reported non-offender trajectory and averaged nearly one and a half times the mean number of officially recorded charges compared to the PGS girls assigned to the self-reported low-rate offender trajectory. Additional Tukey's b one-tailed post hoc tests revealed that the nonoffender trajectory significantly differed from both the low-rate offender trajectory $(p<0.01)$ and the high-rate offender trajectory $(p<0.05)$ and that the low-rate offender trajectory also significantly differed from the high-rate offender trajectory $(p=0.05)$.

Table 2 presents the results of a series of bivariate logistic regression models revealing the odds of having an officially recorded charge for the various selfreported trajectory group comparisons. The odds that a PGS girl in the self-reported low-rate offender moderate and serious theft and/or violence trajectory was officially charged between ages 11-18 were more than three and a half times greater than the odds that a PGS girl in the self-reported non-offender trajectory was officially charged

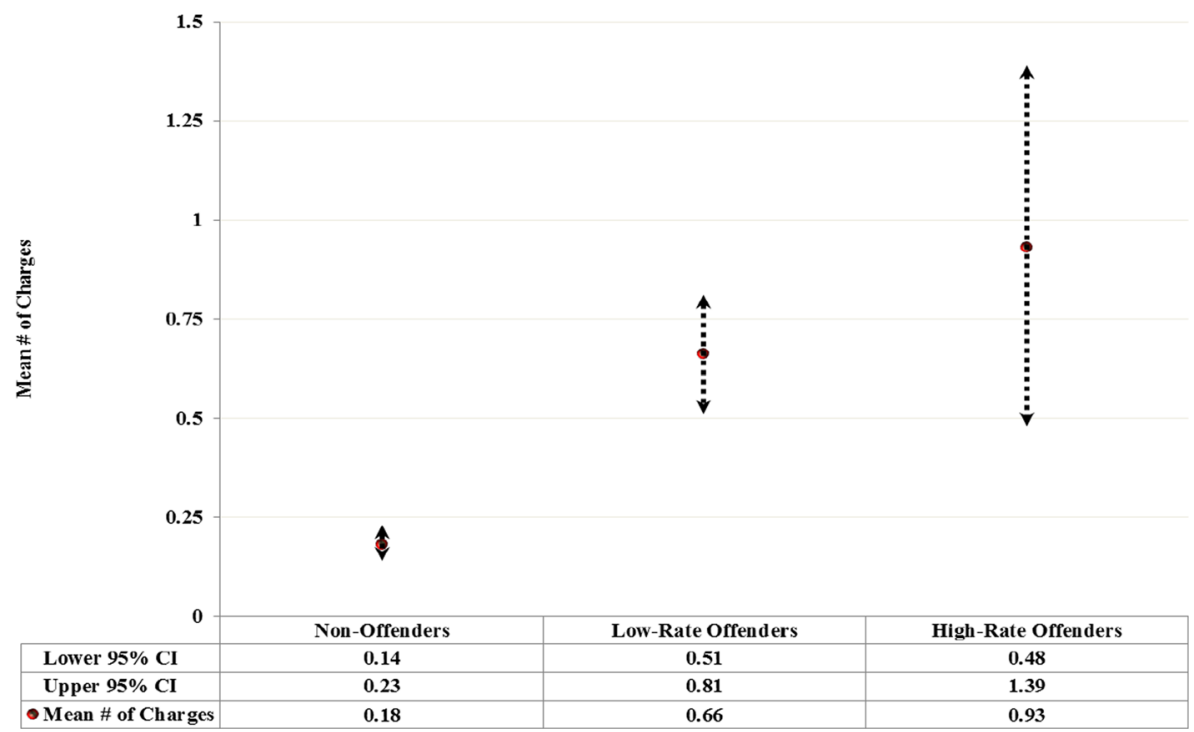

Fig. 2 Mean frequency of official charges for moderate and serious theft and violence (ages 11-18) by PGS moderate and serious theft and violence self-reported offending trajectories (ages 11-18). Note: $(F=39.43$, $d f=2, p<0.001)$. $C I$ confidence interval 
Table 2 Odds of being officially charged with an offense for moderate and serious theft and violence (ages 11-18) by PGS moderate and serious theft and violence self-reported offending trajectories (ages 11-18)

\begin{tabular}{|c|c|c|c|}
\hline & \multirow[t]{2}{*}{ Odds ratio } & \multicolumn{2}{|c|}{$95 \% \mathrm{CI}$} \\
\hline & & Lower & Upper \\
\hline Low rate offenders vs. non-offenders & $3.67 *$ & 2.83 & 4.76 \\
\hline High-rate offenders vs. non-offenders & $7.08 *$ & 3.78 & 13.28 \\
\hline Low rate offenders vs. high-rate offenders & $1.93 *$ & 1.02 & 3.66 \\
\hline
\end{tabular}

CI confidence interval

$p<0.05$

$(\mathrm{OR}=3.67,95 \% \mathrm{CI}=2.83-4.76, p<0.001)$. Furthermore, the odds that a PGS girl assigned to the self-reported high-rate trajectory was officially charged were more than seven times the odds that a PGS girl in the self-reported non-offender trajectory was officially charged $(\mathrm{OR}=7.08,95 \% \mathrm{CI}=3.78-13.28, p<0.001)$. Finally, a PGS girl assigned to the self-reported high-rate offender trajectory had nearly double the odds of being officially charged relative to the odds of a PGS girl assigned to the low-rate offender trajectory being officially charged $(\mathrm{OR}=1.93,95 \% \mathrm{CI}=1.02-3.66, p<0.05)$.

\section{Discussion}

The present study is unique for the USA in presenting trajectories of girls' self-reported offending. Second, the study is unique in establishing the validity of the trajectories in relation to the versatility of self-reported delinquency and the probability of incurring officially recorded police charges. In earlier research on the same sample, Loeber et al. [13] showed that the age-crime prevalence and the age-crime frequency curves according to self-reports of frequency of offending for girls were much lower than the equivalent curves for males. However, in the introduction we hypothesized that the age-crime curve may hide meaningful trajectory differences among offenders in the extent to which they offend and in the extent to which the frequency of their offending changes with age. Largely because of the scarcity of longitudinal studies on delinquency in girls, this important issue has not been sufficiently addressed in the literature. The present results show that the data best fitted three age-crime, self-reported frequency trajectories for girls: non-offenders, low-rate offenders, and high-rate offenders. The frequency of offending pattern for the high-rate female offenders gradually increased between ages 11 and 15 from an average of six self-reported offenses per year to an average of nine offenses per year. With a moderate peak at age 15, the offense frequency pattern then decreased slightly to an average of about 7.5 offenses per year by age 18 .

The findings from the current study are in line with previous research showing a smaller number of trajectories for females than have been identified for males (e.g., [27]: [28], for offender samples; [31]; Shaw, Lacourse, and [40], for normal general samples; see also [29, 32]). Further, the results confirm our hypothesis that the lower aggregate age-crime curve representing all active female offenders found in other 
studies [13] may hide the presence of a small group of high-rate female offenders, who can be identified by means of the trajectory analyses. We also found that compared to low-rate offenders, high-rate offenders were much more versatile in their offending, engaging in both violence and theft. This is a novel finding and important from a theoretical and practical point of view. Consistent with Moffitt's dual taxonomy [25], we found a small group of high-rate, versatile offending girls who resemble the male group of life course persistent offenders. We did not find evidence for the adolescentlimited offenders as described by Moffitt [25].

Importantly, the present study also demonstrated that self-reported trajectories of offending are differentially related to official charges by the police. Specifically, the results show that the odds of a police charge for a girl in the self-reported high-rate offender trajectory between ages 11 and 18 were more than double than for girls in the low-rate offender trajectory, and three and a half times higher than for girls in the nonoffender trajectory. The prevalence and the frequency of police charges also varied significantly across these three trajectory groups. As such, these results support the validity of the distinctions between the three delinquency trajectories based on the girls' self-reports.

The current study has several limitations. The high-rate offender trajectory was small, which is likely to have negatively influenced the power and reliability of the study. One of the explanations for the small size of the high-rate group is that we focused only on the more serious female delinquents and chose to include only selfreported offenses that could be matched with official records, thus excluding status offenses. It is common to include status offenses, especially in studies of female delinquency, to increase the low base rate of offending; however, the aim of the current study was to identify serious female offenders, to possibly match this group with the life course-persistent offenders described by Moffitt [25].

The study does not address whether girls' trajectories for subcategories of high-rate offenders, such as violent, property, or drug offenders, also follow the age-crime curve. It also remains to be seen how the trajectory groups might change when a longer age period of offending is taken into account, particularly when this examination is extended into young adulthood. In addition, the results represent probabilities of group membership rather than the absolute certainty that particular girls belong to one of the empirically derived trajectories. Moreover, the formulation of the trajectories requires the availability of longitudinal data for many girls, and this formulation is postdictive rather than predictive.

Practical implications and future research The results of this study have several implications for intervention practices. The results buttress the presence of a small but serious high-rate offending group of girls. We agree with Lowenkamp and Latessa [43] that these offenders require frequent and most intensive interventions. Second, the present results also show that this category of offenders is already present in late childhood (age 11).

This study has also implications for future research on developmental and life course criminology. First, there is a need to replicate the current self-reported delinquency trajectories for girls in other samples. Second, the field is currently dominated by trajectory analyses based on official records rather than self-reported delinquency. 
Increasingly, however, studies have linked the two types of measurements and have highlighted 'hidden delinquency' in official records which is only apparent when selfreports of offending are used. This may mean that some offenders who are high-rate according to self-reports may look like low-rate offenders in official records. In this sense, knowledge on the scaling-up factor from official records to self-reported delinquency becomes crucial. For example, Ahonen et al. [44] showed that for every police charge in the PGS there were, on average, more than four offenses that went under the radar, and for every girl charged there were, on average, three offenders who were not detected by the police. What this means, in terms of offender classification based on trajectory analyses using official records compared to offender classification based on trajectory analyses using self-reports, remains to be investigated.

Third, theories on female delinquency can best be tested by examining which early predictors (e.g., personal characteristics, background factors, and environmental influences) prospectively discriminate between different trajectory memberships. Thus, the present results offer a template for future prospective analyses that can offer insights into which girls are likely to become high-rate offenders (or escalate to more serious offending levels) and which girls are more likely to remain law-abiding. Only then will trajectory studies come of age and become relevant for the administration of justice for known offenders and for interventions to prevent some girls' increased frequency and severity of offending as they age.

Acknowledgments The first author is grateful to the Swedish Research Council (Vetenskapsrådet) for supporting her research.

This project was supported by Grant \# (2013-JF-FX-0058) awarded by the Office of Juvenile Justice and Delinquency Prevention, Office of Justice Programs, US Department of Justice. The opinions, findings, and conclusions or recommendations expressed in this publication are those of the author(s) and do not necessarily reflect those of the Department of Justice.

The authors are grateful to Rebecca Stallings for proof reading.

\section{References}

1. Farrington, D. P., Piquero, A. R., \& Jennings, W. G. (2013). Offending from childhood to late middle age: recent results from the Cambridge study in delinquent development. New York, NY: Springer.

2. Jennings, W. G., Loeber, R., Pardini, D., Piquero, A., \& Farrington, D. P. (2016). Offending from childhood to young adulthood: recent results from the Pittsburgh youth study. New York, NY: Springer.

3. Shaw, D. S., Lacourse, E., \& Nagin, D. S. (2005). Developmental trajectories of conduct problems and hyperactivity from ages 2 to 10. Journal of Child Psychology and Psychiatry, 46, 931-942.

4. Zahn, M. A., et al. (2008). Violence by teenage girls: trends and contexts. U.S Department of Justice, Office of Justice Programs, Office of Juvenile and Delinquency Prevention.

5. Goodkind, S., Wallace, J. M., Shook, J. J., Bachman, J., \& O’Malley, P. (2009). Are girls really becoming more delinquent? Testing the gender convergence hypothesis by race and ethnicity, 1976-2005. Child and Youth Services Review, 31(8), 885-895.

6. Jennings, W. G. (2011). Sex disaggregated trajectories of status offenders: Does CINS/FINS status prevent male and female youth from becoming labeled delinquent? American Journal of Criminal Justice, 36, 177-187.

7. Farrington, D. P. (1986). Age and crime. In M. Tonry (Ed.), Crime and justice: an annual review of research (Vol. 7). Chicago: University of Chicago Press.

8. Loeber, R., \& Farrington, D. P. (2014). The age-crime curve. In G. Bruinsma \& D. Weisburd (Eds.), Encyclopedia of criminology and criminal justice (pp. 12-18). New York: Springer. 
9. Fabio, A., Tu, L.-C., Loeber, R., \& Cohen, J. (2011). Neighborhood socioeconomic disadvantage and the shape of the age-crime curve. American Journal of Public Health, 101(1), S325-S332.

10. Schulman, E. P., Steinberg, L. D., \& Piquero, A. R. (2013). The age-crime curve in adolescence and early adulthood is not due to age differences in economic status. Journal of Youth and Adolescence, 42(6), 848-8660.

11. Collins, R. (2004). Onset and desistance in criminal careers. Neuro biology and the age-crime relationship. Journal of Offender Rehabilitation, 39(3), 1-19.

12. Block, C. R., Blokland, A. A., van der Werff, C., van Os, R., \& Nieuwbeerta, P. (2010). Long-term patterns of offending in women. Feminist Criminology, 5(1), 73-107.

13. Loeber, R., Hipwell, A. E., Pardini, D. P., Stepp, S. D., \& Ahonen, L. (2015). Constancy and change in the prevalence and frequency of offending when based on longitudinal self-reports or official records: comparisons by gender, race, and crime type. Journal of Developmental and Life Course Criminology, $1,150-168$.

14. Chesney- Lind, M. (1997). The female offender: girls, women and crime. Thousand Oaks, CA: Sage.

15. Blokland, A., \& van Os, R. (2010). Life span offending trajectories of convicted Dutch women. International Criminal Justice Review, 20(2), 169-187.

16. Ferrante, A. M. (2013). Assessing gender and ethnic differences in developmental trajectories of offending. Australian and New Zealand Journal of Criminology, 39, 34-53.

17. Fontaine, N., Carbonneau, R., Vitaro, F., Barker, E. D., \& Tremblay, R. E. (2009). Research review: a critical review of studies on the developmental trajectories of antisocial behavior in females. Journal of Child Psychology \& Psychiatry, 50, 363-385.

18. Huizinga, et al. (2013). Developmental sequences of girls' delinquent behavior. U.S Department of Justice, Office of Justice Programs, Office of Juvenile and Delinquency Prevention.

19. Leeper- Piquero, N., \& Sealock, M. D. (2004). Gender and general strain theory: a preliminary test of Broidy and Agnew's gender/GST hypothesis. Justice Quarterly, 21, 125-158.

20. Silverthorn, P., \& Frick, P. J. (1999). Developmental pathways to antisocial behavior: the delayed-onset pattern in girls. Development \& Psychopathology, 11, 101-126.

21. White, N. A., \& Piquero, A. R. (2004). A preliminary empirical test of Silverthorn and Frick's delayedonset pathway in girls using an urban, African-American, US-based sample. Criminal Behaviour \& Mental Health, 14(4), 291-309.

22. Jennings, W. G., Maldonado-Molina, M., \& Komro, K. A. (2010). Sex similarities/differences in trajectories of delinquency among urban Chicago youth: the role of delinquent peers. American Journal of Criminal Justice, 35, 56-75.

23. Fergusson, D. M., \& Horwood, J. L. (2002). Male and female offending trajectories. Development and Psychopathology, 1, 159-177.

24. Maldonado-Molina, M. M., Jennings, W. G., \& Komro, K. A. (2010). Effects of alcohol on trajectories of physical aggression among urban youth: an application of latent trajectory modeling. Journal of Youth and Adolescence, 39, 1012-1026.

25. Moffitt, T. E. (1993). Adolescence-limited and life-course-persistent antisocial behavior: a developmental taxonomy. Psychological Review, 100(4), 674-701.

26. Landsheer, J. A., \& van Dijkum, C. (2005). Male and female delinquency trajectories from pre through middle adolescence and their continuation in late adolescence. Adolescence, 40(160), 729-748.

27. Piquero, A. R., Brame, R., Mazerolle, P., \& Haapanen, R. (2002). Crime in emerging adulthood. Criminology, 40, 137-169.

28. Sampson, R. J., \& Laub, J. H. (2013). Life-course desisters? Trajectories of crime among adolescent boys followed to age 70. Criminology, 41, 555-592.

29. Piquero, A. R. (2008). Taking stock of developmental trajectories of criminal activity over the life course. In A. M. Liberman (Ed.), The long view of crime: a synthesis of longitudinal research (pp. 23-79). NY: Springer.

30. Piquero, A. R., Blumstein, A., Brame, R., Haapenen, R., Mulvey, E. P., \& Nagin, D. S. (2001). Assessing the impact of exposure time and incapacitation on longitudinal trajectories of criminal offending. Journal of Adolescent Research, 16, 54-74.

31. Broidy, L. M., Nagin, D. S., Tremblay, R. E., Bates, J. E., Brame, R., Dodge, K. A., et al. (2003). Developmental trajectories of childhood disruptive behaviors and adolescent delinquency: a six site, cross-national study. Developmental Psychology, 39, 222-245.

32. Jennings, W. G., \& Reingle, J. (2012). On the number and shape of developmental/life-course violence, aggression, and delinquency trajectories: a state-of-the-art review. Journal of Criminal Justice, $40,472-489$. 
33. Theobald, D., Farrington, D. P., Loeber, R., Pardini, D. A., \& Piquero, A. R. (2014). Scaling up from convictions to self-reported offending. Criminal Behaviour and Mental Health, 24(4), 265-276.

34. Hipwell, A. E., Loeber, R., Stouthamer Loeber, M., Keenan, K., White, H. R., \& Kroneman, L. (2002). Characteristics of girls with early onset disruptive and antisocial behaviour. Criminal Behaviour and Mental Health, 12, 99-118.

35. Keenan, K., Hipwell, A. E., Stouthamer-Loeber, M., Loeber, R., \& McTigue, K. (2010). The Pittsburgh girls study: overview and initial findings. Journal of Clinical Child and Adolescent Psychology, 39, 506-521.

36. Elliott, D. S., Huizinga, D., \& Ageton, S. S. (1985). Explaining delinquency and drug use. Beverly Hills, CA: Sage.

37. Stouthamer-Loeber, M., \& Stallings, R. (2008). Measurement instruments and contructs. In R. Loeber, D. P. Farrington, M. Stouthamer-Loeber, \& H. White (Eds.), Violence and serious theft: development and prediction from childhood to adulthood (pp. 39-73). New York: Routledge.

38. Loeber, R., Farrington, D. P., Stouthamer-Loeber, M., \& White, H. R. (2008). Violence and serious theft: development and prediction from childhood to adulthood. New York: Routledge.

39. Jones, B. L., Nagin, D. S., \& Roeder, K. (2001). A SAS procedure based on mixture models for estimating developmental trajectories. Sociological Methods \& Research, 29, 374-393.

40. Nagin, D. S. (2005). Group-based modeling of development. Cambridge, Massachusetts: Harvard University Press.

41. Nagin, D. S. (2010). Group-based trajectory modeling: an overview. In A. R. Piquero \& D. Weisburd (Eds.), Handbook of quantitative criminology (pp. 53-67). New York: Springer.

42. Nagin, D., \& Odgers, C. L. (2010). Group-based trajectory modeling in clinical research. Annual Review of Clinical Psychology, 6, 109-138.

43. Lowenkamp, C. T., \& Latessa, E. J. (2004). Increasing the effectiveness of correctional programming through the risk principle: identifying offenders for residential placement. Criminology and Public Policy, $4(1), 501-528$.

44. Ahonen, L., Loeber, R., Farrington, D. P., Hipwell, A. E., \& Stepp, S. D. (2016). What is the hidden figure of delinquency in girls? Scaling up from police charges to self-reports. accepted for publication at Victims and Offenders. 